\title{
Análise de dados de reclamações em empreendimentos habitacionais de interesse social: estudo no Programa de Arrendamento Residencial
}

\author{
Analysis of complaint data in social house-building \\ projects: a study in the Residential Leasing Program
}

\section{Juliana Nunes de Sá Brito \\ Carlo Torres Formoso \\ Márcia Elisa Echeveste}

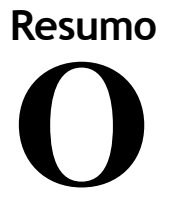

informação ma gestão de empreendimentos, sendo pouçs as empresas que percebem a utilidade das informações sobre reclamações. $O$ presente trabalh apresenta uma análise de dados de reclamações de usuários de uma amostra de empreendimentos habitacionais de interesse social, com o objetivo de investigar sua utilidade para a retroalimentação do processo de desenvolvimento do produto nesse segmento. Foram analisadas 6.956 reclamações de usuários de 42 empreendimentos habitacionais de interesse social do Programa de Arrendamento Residencial, localizados no estado do Rio Grande do Sul. O trabalho envolveu um tratamento inicial dos dados de reclamações para a montagem de um banco de dados, seguido da aplicação de diversos testes estatísticos. As principais contribuições estão relacionadas com a utilidade dos dados de reclamações, incluindo a geração de indicadores que podem apoiar a tomada de decisão por parte de diferentes agentes envolvidos na produção habitacional, tais como

Juliana Nunes de Sá Brito Núcleo Orientado para a Inovação da Edificação Universidade Federal do Rio Grande Rua Osvaldo Aranha, 99, Centro Porto Alegre - RS - Brasil CEP 90050-100 Tel.: (51) 3308-3518 E-mail: julianabrito.arq@gmail.com

Carlos Torres Formoso Núcleo Orientado para a Inovação da Edificação Universidade Federal do Rio Grande E-mail: formoso@ufrgs.br

Márcia Elisa Soares Echeveste Departamento de Estatística, Instituto de Matemática Universidade Federal do Rio Grande
do Sul Av. Oswaldo Aranha, 99, sala 508, Centro Porto Alegre - RS - Brasil CEP 90035-190 Tel.: (51) 3308-4297 E-mail: echeveste@producao.ufrgs.br

Recebido em 16/11/10 Aceito em 11/10/11 projetistas, construtoras, agentes financiadores e empresas envolvidas na gestão da operação e manutenção. Os indicadores, se bem utilizados, podem contribuir para a melhoria de produtos e serviços que compreendem os empreendimentos habitacionais, possibilitando um aumento na satisfação dos usuários finais.

Palavras-chave: Reclamações. Habitação de interesse social. Retroalimentação. Desenvolvimento do produto.

\section{Abstract}

The management of complaints is a widely adopted practice among manufacturing companies, as a way of improving the quality of products and services. Regarding construction, there are very few studies on the use of this type of information in project management, as well as there seems to be only a few companies that understand the utility of complaints. This paper presents an analysis of user complaints from a sample of social house-building projects, aiming at investigating the utility of this type of data to provide feedback for the product development process. A database of 6,956 complaints from 42 house-building projects was analysed, all of them located in the state of Rio Grande do Sul, funded by the Residential Leasing Program. Initially, the study involved the preparation of the database, followed by the application of statistical tests. The main contributions are related to the utility of the complaint data, including the generation of metrics that can support decision making by different stakeholders in social housing projects, including designers, construction companies, financing institutions, and facilities management companies. Those metrics, if appropriately used, may contribute to improve the set of products and services that form social housing projects, and improve the degree of satisfaction of final users.

Keywords: Complaints. Social house projects. Feedback. Product development. 


\section{Introdução}

A busca por melhoria da qualidade da habitação de interesse social tem sido abordada como um tema de grande importância nos campos social e econômico brasileiros. Tal preocupação não se restringe às empresas privadas que produzem as habitações, mas estende-se ao poder público, o qual é responsável pela provisão habitacional do país e, por vezes, pela gestão da operação e manutenção dos imóveis.

Em diversos setores industriais e de serviços, a aplicação de conceitos e de ferramentas de marketing tem contribuído para aumentar a qualidade dos produtos com base na captação dos requisitos dos clientes, assim como da consideração destes no desenvolvimento de novos produtos. Da mesma forma, na indústria da construção civil é preciso caracterizar os usuários das habitações e conhecer com profundidade suas necessidades e expectativas, para que a satisfação deles possa ser alcançada. No entanto, quando os requisitos dos usuários não são atendidos, $\log o$ surge a insatisfação como consequência da aquisição de um produto ou da prestação de um serviço que lhe foi feito (HUPPERTZ, 2007), o que pode ocasionar diversas formas de reação do usuário, começando, muitas vezes, com a efetuação de uma reclamação, a troca de fornecedor ou a retaliação 1 à empresa (JAMBEKAR; PELC, 2005; SINGH, 1988).

Dessa forma, as reclamações surgem como uma importante fonte de informações advinda do usuário e podem ser consideradas como uma declaração de expectativas não satisfeitas e, portanto, uma oportunidade para a melhoria do setor habitacional. Existem diversas formas de se captarem os requisitos dos clientes, além das reclamações, algumas mais onerosas e menos diretas, tais como análises das expectativas de clientes em indústrias paralelas, utilização de pessoas disfarçadas em compradores, auditorias externas e pesquisas formais. Entretanto, o registro das reclamações constitui uma forma direta $e$ pouco dispendiosa de obter informações e entender as expectativas dos usuários sobre produtos e serviços (BARLOW; MOLLER, 1996), auxiliando no processo de tomada de decisão do processo de desenvolvimento de produtos ${ }^{2}$ (PDP).

\footnotetext{
${ }^{1}$ A retaliação pode ser entendida como uma represália, desforra ou desagravo e se faz presente num momento de tensão, de disputa, no qual uma das partes tenta de forma estratégica recuperar uma perda sofrida (FERNANDES, 2008).

${ }^{2}$ Rozenfeld et al. (2006) definem PDP como a concepção, projeto, produção e acompanhamento de um produto após a entrega final ao cliente. Tendo em vista que os empreendimentos de construção são desenvolvidos segundo as mesmas etapas, considera-se que a realização de um
}

Por outro lado, o comportamento que leva às reclamações por parte dos consumidores é frequentemente repudiado por muitas empresas. Segundo Barlow e Moller (1996), há empresas que não gostam de ouvir reclamações, pois atribuem a elas uma reputação negativa de seu próprio negócio, uma vez que reclamações são consideradas como uma imputação negativa que, nos termos legais, se referencia a um comportamento culposo.

Entretanto, as empresas mais desenvolvidas e voltadas ao consumidor vêm encorajando seus clientes a reclamarem diretamente para seus representantes (BARLOW; MOLLER, 1996; FISHER, et al., 1999). Essa atitude permite à empresa remediar a reclamação do cliente, além de captar informações importantes para melhorar seus produtos e serviços (RUST; STEWART, 1996; FISHER et al., 1999).

Para que as reclamações sejam efetivamente utilizadas no PDP, é necessário que elas sejam devidamente processadas, analisadas e repassadas aos tomadores de decisão. No entanto, muitas empresas não conseguem se beneficiar dessas informações, uma vez que, segundo Sampson (1999), pouco investimento é feito nos sistemas de feedback dos clientes e, com isso, raramente esses sistemas auxiliam as empresas na identificação das preferências de seus clientes. Outro fator que dificulta o gerenciamento das reclamações é a falta de aptidão das empresas para exercer essa tarefa (BARLOW; MOLLER, 1996). Por exemplo, em um estudo realizado em três empresas de manufatura na Suécia, elas não possuíam uma estrutura formal para transferir o feedback dos clientes até o processo de desenvolvimento de novos produtos, embora estivessem dispostas a utilizar esse feedback como forma de melhorar o PDP (FUNDIN; BERGMAN, 2003). Apesar dos potenciais benefícios da utilização das reclamações tanto para o cliente quanto para a empresa, há pouquíssimos estudos na literatura sobre a utilização dessas informações para a melhoria da qualidade habitacional (YU; HAN, 2001).

O presente artigo apresenta uma análise de dados de reclamações de usuários de uma amostra de empreendimentos habitacionais de interesse social, com o objetivo de investigar sua utilidade para a retroalimentação do processo de desenvolvimento do produto nesse segmento. O foco do estudo está na utilização de dados de reclamações para apoiar a tomada de decisão nas etapas de projeto,

empreendimento da construção também pode ser entendida como PDP. 
produção e gestão da operação e manutenção. Este trabalho foi baseado na análise de um banco de dados de reclamações de empreendimentos do Programa de Arrendamento Residencial (PAR), no estado do Rio Grande do Sul.

O PAR foi uma modalidade de provisão habitacional financiada pela Caixa Econômica Federal sob a forma de arrendamento entre 1999 e 2009, ano em que surgiu o programa Minha Casa, Minha Vida, o qual passou a abranger o PAR, bem como outros programas do Governo. Em função da particularidade do PAR quanto à propriedade das unidades habitacionais, as quais são de propriedade da Caixa por um período de, no mínimo, cinco anos, a administração dos imóveis vem sendo realizada por meio da contratação de empresas administradoras (imobiliárias). Nesse caso, a administração engloba os aspectos da manutenção, da operação e do suporte necessário às atividades desenvolvidas na edificação e em seus espaços coletivos. Assim, a empresa administradora é responsável por atender às solicitações e gerenciar as reclamações recebidas pelos usuários, o que representa uma oportunidade para investigar o potencial papel dessas informações no processo de desenvolvimento do produto de empreendimentos habitacionais de interesse social.

\section{Incidência de reclamações e retroalimentação na construção habitacional}

Embora haja incentivo às reclamações por parte de algumas empresas, com freqüência clientes atribuem o ato de reclamar a uma fonte adicional de aborrecimentos e a uma perda de tempo (BARLOW; MOLLER, 1996). Segundo a TARP ${ }^{3}$, a omissão das reclamações pode chegar à ordem de 26 em cada 27 pessoas que recebem serviços deficientes (BARLOW; MOLLER, 1996). Uma pesquisa mais recente, realizada pela universidade da Pensilvânia, ${ }^{4}$ afirma que somente $6 \%$ dos consumidores que enfrentaram algum tipo de problema reclamam para a empresa (HUPPERTZ, 2007).

No entanto, essa proporção pode variar, uma vez que depende de diferentes fatores, tais como o valor da aquisição, a concorrência existente no mercado do produto ou serviço, o grupo socioeconômico ao qual o cliente pertence, os custos e benefícios da reclamação, a tendência

\footnotetext{
${ }^{3}$ Technical Assistance Research Programs.

${ }^{4}$ Retail Customer Dissatisfaction Study (2006), Retail Customer Dissatisfaction Study, Verde Baker Retail Initiative at Wharton, University of Pennsylvania, Philadelphia, PA.
}

individual do cliente em reclamar e a importância que a compra tem para o cliente (BARLOW; MOLLER, 1996).

No caso da habitação, o valor da aquisição é considerado alto, e a importância da compra para o cliente é grande, uma vez que muitas pessoas fazem uma única aquisição desse tipo de produto por toda a vida. Nesse caso, segundo Barlow e Moller (1996), os clientes geralmente reclamam porque a restituição vale o sacrifício da reclamação. Segundo Kim (2003), a restituição de uma reclamação está relacionada com o valor percebido que os usuários têm da reclamação, ou seja, o usuário reclama quando tem expectativa de que os benefícios superem os sacrifícios da reclamação (KIM, 2003). Para Saliba e Fisher (2000), os benefícios percebidos estão relacionados à solução proporcionada de um problema, ao prazer ou satisfação dado ao cliente e ao desempenho do produto em certas tarefas ou funções. Os sacrifícios percebidos, por sua vez, incluem os sacrifícios monetários relacionados à quantidade de dinheiro que o cliente tem de pagar para adquirir determinado produto ou serviço, ou para efetuar uma reclamação; sacrifícios temporais relacionados ao tempo de espera para a aquisição do produto ou serviço, ou para a resolução do problema reclamado; sacrifícios psicológicos, os quais envolvem a energia e a tensão incorrida na realização de compras importantes, na aceitação dos riscos de que os produtos e serviços podem não ter o desempenho esperado; sacrifícios comportamentais que envolvem o esforço físico despendido para a compra de um produto, recebimento de um serviço ou efetuação de uma reclamação (CHURCHILL; PETER JUNIOR, 2000; RAVALD; GRÖNROOS, 1996). O trade-off da geração de uma reclamação também pode estar relacionado à percepção prévia do usuário quanto à resolução do problema (KIM, 2003). Essa percepção depende dos canais de reclamações disponibilizados aos usuários e da satisfação destes com o gerenciamento das reclamações prévias (KIM, 2003).

Normalmente é na etapa de gestão da operação e da manutenção que há a manifestação dos usuários quanto a reclamações, as quais podem ser decorrentes de decisões tomadas nas etapas anteriores do PDP. A etapa de concepção e projeto é apontada por diversos autores como a origem das relações perceptivas entre o indivíduo e o espaço, as quais podem contribuir para a criação de uma imagem coletiva positiva ou negativa do ambiente (LYNCH, 1960; LAY; REIS, 2005a; LAY; REIS, 2005b). Para Lay e Reis (2005b), as características de um projeto arquitetônico, tais como aparência visual e organização espacial influenciam o 
comportamento dos usuários tornando-os satisfeitos ou insatisfeitos como o ambiente construído. Para os referidos autores, esses fatores são capazes de incentivar a apropriação positiva dos espaços comuns, afetando positivamente as formas de gerenciamento, a manutenção e a imagem do conjunto habitacional. Essas relações são corroboradas por estudos feitos por Reis (1998), nos quais são identificadas as relações existentes entre níveis de manutenção, limpeza, aparências externa e interna e a satisfação dos moradores.

Muitas reclamações têm origem nas chamadas falhas construtivas ou patologias, as quais podem ser causadas por problemas construtivos ou de projeto, tais como ausência de detalhamento ou incompatibilidade de projetos (FELD, 1968). Em geral, as falhas resultam em reclamações à medida que requisitos básicos dos usuários não são atendidos e eles se tornam insatisfeitos (JAMBEKAR; PELC, 2005).

$\mathrm{Na}$ etapa de uso dos empreendimentos é possível identificar conflitos comportamentais, geralmente relacionados à solução de projeto ou decorrente de uma gestão ineficaz (SOUZA, 1988; SEELEY, 1976; LAY; REIS, 2005b; DUNOWICZ; HASSE; 2005; BLANCO; MARTÍNEZ; JARPA, 2003). Os aspectos físico-espaciais de um ambiente construído, ao produzir percepções distintas em seus usuários, podem influenciar o comportamento das pessoas que nele vivem, tornando-as insatisfeitas com o ambiente (LAY; REIS, 2005b), o que, potencialmente, pode gerar reclamações.

Para que se possa obter uma melhoria de qualidade do setor habitacional, com base em utilização de reclamações, é necessário que o setor entenda a utilidade delas e que introduza métodos de gestão desse tipo de informação como uma estratégia de negócio. Para Vos e Huitema (2008), o gerenciamento de reclamações engloba ações operacionais de atendimento às reclamações e também o planejamento e análise dessas ações em longo prazo. Segundo os mesmos autores, essa análise permite a identificação de falhas internas e externas no processo da empresa, além de apontar as necessidades básicas ou esperadas do cliente, as quais não foram atendidas.

No entanto, o tratamento de reclamações, o qual consiste em uma atividade operacional destinada a solucionar o problema do consumidor, não pode ser confundido com o gerenciamento das reclamações (complaint handling process), que constitui um processo mais complexo (VOS; HUITEMA, 2008). Segundo Estelami (2000), o gerenciamento das reclamações deve considerar três aspectos: (a) o retorno ao consumidor, o que se refere a medidas de restituição, substituição do produto, reparos e pagamento de despesas adicionais causadas por falha da empresa;

(b) o comportamento e a interação do funcionário com o consumidor, que devem demonstrar que a empresa está interessada em resolver o problema do consumidor; e

(c) rapidez e comprometimento no atendimento.

Um processo eficaz de gerenciamento das reclamações deve englobar a coleta e a análise dos dados ao longo do tempo, a identificação de problemas repetitivos e sistêmicos, a proposição de soluções para as principais causas, independentemente de esses problemas terem sido causados pelo produto ou serviço, pelas pessoas ou pelo processo em que ele está inserido (ANG; BUTTLE, 2006; BARLOW; MOLLER, 1996). Segundo Ang e Buttle (2006), as reclamações proporcionam às empresas oportunidades de aprendizado, nas quais se pode identificar os problemas do negócio e, com isso, aumentar a retenção de clientes. Assim, é fundamental dar mais importância às informações geradas na etapa de uso de produtos ou serviços para que se possa contribuir com a melhoria deles de uma maneira mais abrangente, retroalimentando as etapas que compõem o PDP de empreendimentos habitacionais.

\section{Método}

A estratégia de pesquisa adotada consistiu na análise de uma base de dados de 6.956 reclamações de usuários de 42 empreendimentos habitacionais de interesse social do Programa de Arrendamento Residencial, promovido pelo Governo Federal, com tempo de ocupação entre 3 e 5 anos, localizados no estado do Rio Grande do Sul. Os dados analisados são de fonte secundária, provenientes do sistema de informação de uma empresa $^{5}$ de administração condominial entre dezembro de 2002 e setembro de 2006.

O sistema de informação da administradora em estudo permite monitorar as reclamações e as solicitações dos usuários dos empreendimentos. Para gerar uma reclamação é necessário que o usuário declare sua solicitação mediante um registro no livro de ocorrências localizado na portaria, um telefonema para a administradora, uma conversa direta com o síndico, o envio de email para a administradora. Posteriormente, a reclamação é registrada por um funcionário da

\footnotetext{
${ }^{5}$ A empresa analisada administra $72 \%$ dos empreendimentos habitacionais de interesse social do Programa de Arrendamento Residencial do estado do Rio Grande do Sul.
} 
administradora em um formulário eletrônico chamado de ordem de serviço, apresentado na Figura 1.

Embora a ordem de serviço apresente vários campos de informações, nem todos eram utilizados pela empresa administradora. Alguns campos, tais como fornecedor, orçamento, tempo (lista) e tempo (total) normalmente não eram preenchidos pelos funcionários. Além disso, observou-se no campo tipo de serviço que a classificação dada à solicitação não se referia ao problema propriamente dito (problema construtivo, problema de manutenção, etc.), mas ao funcionário da administradora responsável pela solução do problema.

A fim de organizar os dados e possibilitar as análises desta pesquisa, as ordens de serviço foram divididas em três categorias. $\mathrm{O}$ agrupamento foi realizado a partir da associação de palavras-chave contidas no campo descrição das ordens de serviço. As categorias são:

(a) Problemas construtivos: consistem em reclamações relacionadas às manifestações patológicas ou falhas ocorridas nos empreendimentos originadas nas etapas de projeto e execução;

(b) Problemas de manutenção: são gerados na etapa de uso e representam reclamações relacionadas às falhas ocorridas pelo mau uso do empreendimento e suas instalações, além de danos causados por atos de vandalismo; e

(c) Problemas comportamentais: são gerados na etapa de uso e consistem em reclamações decorrentes de conflitos relacionados ao comportamento humano, causados pela ação de moradores, tais como discussão entre moradores e funcionários da administradora, desrespeito aos demais usuários do empreendimento, desordens provocadas por reações exacerbadas dos moradores.
Uma das dificuldades encontradas para a classificação das reclamações que atingem sistemas ou elementos construtivos foi a incerteza quanto a suas origens (problemas construtivos ou de manutenção), devido à descrição insuficiente e inadequada dos problemas. Ao analisar uma reclamação imprecisa, levou-se em consideração a data de ocupação do empreendimento em estudo e a data da reclamação. Para reclamações realizadas até o sexto mês de ocupação, consideraram-se os problemas como sendo referentes à construção. Para as reclamações realizadas após o sexto mês de ocupação, consideraram-se os problemas como sendo referentes à manutenção, uma vez que seria pouco provável um usuário habitar sua unidade durante seis meses e conviver com um problema construtivo sem realizar uma reclamação.

Posteriormente, procedeu-se à montagem do banco de dados com base nas categorias das reclamações e na associação delas com as características físicas dos empreendimentos e com as atividades ou decisões relacionadas ao desenvolvimento dos empreendimentos habitacionais, conforme apresentado na Quadro 1.

Para cada teste realizado foi necessário utilizar uma subamostra, de acordo com o tipo do problema analisado e com a idade dos empreendimentos. Dependendo do tipo de análise, foram consideradas as reclamações realizadas no primeiro ano de ocupação, do primeiro ao terceiro ano e do primeiro ao quinto ano de ocupação, conforme a Quadro 1. Além desse condicionante, as subamostras também se limitaram à disponibilidade dos registros de reclamações, ou seja, em alguns empreendimentos as reclamações não haviam sido registradas em determinado período por falha da administradora. Nesses casos, os empreendimentos foram desconsiderados da análise.

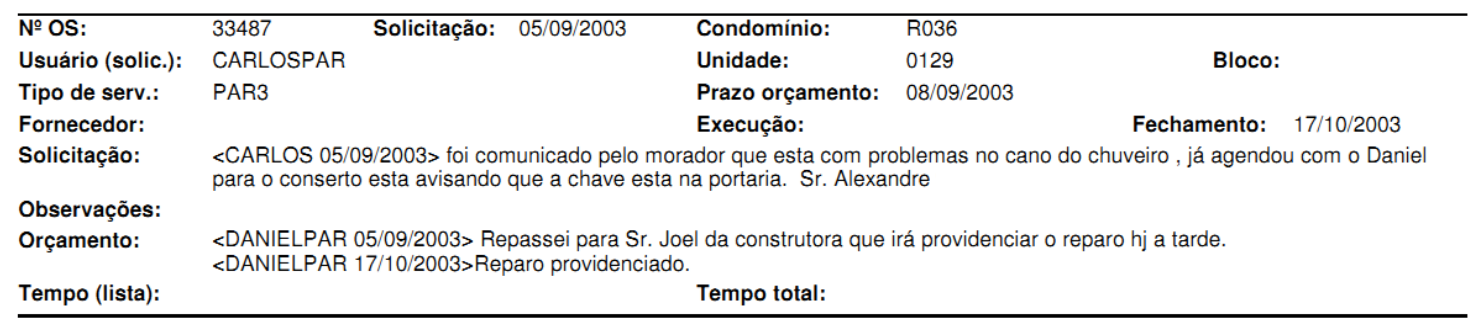

Figura 1 - Ordem de Serviço da Administradora A 


\begin{tabular}{|c|c|c|c|}
\hline & Objetivo & Teste realizado & $\begin{array}{l}\text { Subamostra } \\
\left(\mathbf{n}^{\mathbf{0}} \text { de }\right. \\
\text { reclamações }) \\
\end{array}$ \\
\hline \multirow{4}{*}{ 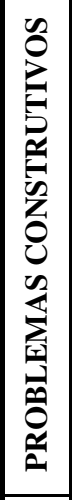 } & $\begin{array}{l}\text { Identificar os sistemas que mais geram } \\
\text { reclamações relacionadas a problemas } \\
\text { construtivos nos cinco primeiros anos de } \\
\text { ocupação. }\end{array}$ & $\begin{array}{l}\text { Análise de frequências de reclamações por } \\
\text { sistema nos cinco primeiros anos de } \\
\text { ocupação dos empreendimentos. }\end{array}$ & 4.259 \\
\hline & $\begin{array}{l}\text { Identificar as reclamações mais críticas } \\
\text { considerando os sistemas que mais geram } \\
\text { reclamações. }\end{array}$ & $\begin{array}{l}\text { Análise de frequências de reclamações por } \\
\text { sistema nos cinco primeiros anos de } \\
\text { ocupação dos empreendimentos. }\end{array}$ & 4.259 \\
\hline & $\begin{array}{l}\text { Identificar o comportamento das reclamações } \\
\text { de acordo com cada empresa construtora. }\end{array}$ & $\begin{array}{l}\text { Análise de frequências de reclamações por } \\
\text { sistema no primeiro ano de ocupação em } \\
\text { relação a cada empresa construtora. }\end{array}$ & 2.581 \\
\hline & $\begin{array}{l}\text { Agrupar as construtoras por valor médio de } \\
\text { reclamação/uh: baixo, médio e alto. }\end{array}$ & $\begin{array}{l}\text { Teste de comparação das médias dos } \\
\text { problemas (One way ANOVA) e Post Hoc } \\
\text { Tukey, complemento da ANOVA. }\end{array}$ & 2.581 \\
\hline \multirow{3}{*}{ 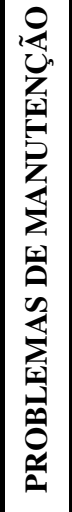 } & $\begin{array}{l}\text { Identificar os sistemas que mais geram } \\
\text { reclamações relacionadas a problemas de } \\
\text { manutenção nos cinco primeiros anos de } \\
\text { ocupação. }\end{array}$ & $\begin{array}{l}\text { Análise de frequências de reclamações nos } \\
\text { sistemas mais críticos nos primeiros cinco } \\
\text { anos de ocupação (cálculo da média de } \\
\text { reclamações/uh em cada sistema). }\end{array}$ & 2.556 \\
\hline & $\begin{array}{l}\text { Identificar as reclamações mais críticas } \\
\text { considerando os sistemas que mais geram } \\
\text { reclamações. }\end{array}$ & $\begin{array}{l}\text { Análise de frequências de reclamações por } \\
\text { sistema nos cinco primeiros anos de } \\
\text { ocupação dos empreendimentos. }\end{array}$ & 2.556 \\
\hline & $\begin{array}{l}\text { Identificar se há relação entre os principais } \\
\text { problemas de manutenção dos } \\
\text { empreendimentos e a realização do TTS. }\end{array}$ & $\begin{array}{l}\text { Teste-T de amostras independentes para os } \\
\text { empreendimentos com três anos de } \\
\text { ocupação. }\end{array}$ & 356 \\
\hline 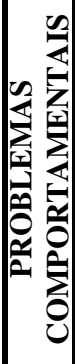 & $\begin{array}{l}\text { Identificar se há relação entre os principais } \\
\text { problemas comportamentais dos } \\
\text { empreendimentos e a tipologia arquitetônica } \\
\text { deles. }\end{array}$ & $\begin{array}{l}\text { Teste-T de amostras independentes para os } \\
\text { empreendimentos com três anos de } \\
\text { ocupação. }\end{array}$ & 356 \\
\hline
\end{tabular}

Quadro 1 - Objetivos e análises realizadas

À medida que os dados foram processados e analisados, foram realizadas algumas discussões com agentes envolvidos na provisão e manutenção dos empreendimentos habitacionais, tais como síndicos dos empreendimentos (que eram funcionários das empresas administradoras) e técnicos vinculados à Caixa Econômica Federal, e também pesquisadores atuantes na área de habitação de interesse social. A seguir são brevemente descritos os seminários.

(a) Seminário 1: contou com a participação de aproximadamente 15 pessoas, entre elas pesquisadores da Universidade Federal do Rio Grande do Sul (UFRGS), da Universidade Federal de Pelotas (UFPel) e representantes da Gerência
Nacional de Infraestrutura e Patrimônio de Terceiros (GIPT) da Caixa. Seu objetivo foi obter percepções dos técnicos da GIPT sobre as análises iniciais realizadas, e identificar outros interlocutores para a discussão dos resultados;

(b) Seminário 2: contou com a presença de pesquisadores da UFRGS, arquitetos e engenheiros da Gidur, totalizando aproximadamente 45 participantes. Seu objetivo foi a apresentação e discussão das análises das reclamações relativas a problemas construtivos, pois os técnicos da Gidur são responsáveis pelo monitoramento dos empreendimentos e, consequentemente, interessados nos problemas construtivos que ocorrem nas obras. A discussão com os agentes da

156 Brito, J. N. de S.; Formoso, C. T.; Echeveste, M. E. S. 
Caixa permitiu refinar a análise de dados e contribuiu na formulação de algumas hipóteses adicionais; e

(c) Seminário 3: contou com a participação do gerente da empresa administradora e de sete síndicos de empreendimentos PAR analisados. Foram discutidos os dados de reclamações, visando sanar dúvidas sobre a forma de registro das ordens de serviço e aprimorar a estrutura de classificação adotada para o banco de dados.

A partir das discussões com pesquisadores e agentes envolvidos na provisão e manutenção dos empreendimentos habitacionais, as análises foram associadas ao tipo de problema descrito na reclamação e a uma etapa do processo de desenvolvimentos dos empreendimentos, ou a uma etapa de tomada de decisão na qual as reclamações poderiam contribuir.

Algumas limitações deste estudo devem ser apontadas, em função da natureza dos dados secundários utilizados na análise:

(a) a descrição dos problemas construtivos e de manutenção muitas vezes é baseada somente no relato dos arrendatários, já que não era realizada de forma sistemática pela empresa administradora uma avaliação técnica dos problemas apontados;

(b) a descrição do problema é inserida por um funcionário da empresa administradora, que pode não ser fiel ao relato dos arrendatários; e

(c) a maioria das ordens de serviço não eram fechadas, não sendo seu conteúdo alterado após a investigação e a solução do problema.

Em suma, é possível que existam diversas imprecisões nos dados disponíveis, que poderiam ser evitadas mediante a introdução de melhorias na forma de gerenciar a informação pela empresa administradora e demais participantes da etapa de operação e manutenção dos empreendimentos. Por outro lado, trata-se de uma base de dados de difícil obtenção no segmento de habitação de interesse social, cuja análise pode indicar oportunidades de utilização de dados dessa natureza.

\section{Resultados}

Os resultados deste estudo são apresentados de acordo com o tipo de problema encontrado nas reclamações. Ao analisar 6.956 reclamações, verificou-se que $61 \%$ estão relacionadas aos problemas construtivos, seguidas das reclamações relacionadas a problemas de manutenção $(29 \%)$ e a problemas comportamentais $(10 \%)$, como mostra a Figura 2.

\section{Problemas construtivos}

Os problemas construtivos foram categorizados com base em dois critérios: manifestação patológica; ${ }^{6}$ ou por sistemas ${ }^{7}$ da edificação. Com base nessa classificação, realizou-se uma análise de frequência dos sistemas e das principais manifestações patológicas de cada sistema, conforme as Figuras 3 e 4.

Verifica-se que $87 \%$ das reclamações relacionadas aos problemas construtivos são representadas pelos sistemas prediais, vedações horizontais, esquadrias e vedações verticais. Essas evidências apontaram para a necessidade de um aprofundamento nas análises das reclamações ocorridas nessas categorias, considerando os problemas construtivos relacionados aos sistemas com maior percentual de ocorrência de reclamações. Realizou-se a análise somente para o conjunto de falhas que somadas representam mais de $70 \%$ das reclamações, conforme a Figura 4.

Observa-se que as reclamações de vazamento e entupimento são os problemas mais recorrentes nos sistemas prediais. Esses problemas podem estar relacionados com o projeto ou com a execução dos empreendimentos, porém a identificação da origem dos problemas não fez parte do escopo deste trabalho pela limitação dos dados disponíveis.

No sistema de vedações verticais observa-se que $75 \%$ das reclamações estão concentradas nos problemas de fissuras e infiltração nas paredes, as quais são de alvenaria estrutural. Essa evidência é corroborada pelo estudo de Richter (2007), o qual aponta as fissuras e a umidade nas paredes como as manifestações mais frequentes em um estudo de seis empreendimentos habitacionais de interesse social do Rio Grande do Sul.

\footnotetext{
${ }^{6}$ Entende-se por manifestação patológica toda manifestação cuja ocorrência ao longo do ciclo de vida de uma edificação venha a prejudicar o desempenho esperado do edifício e de suas partes (sistema, componente e elemento) (ABNT, 2008).

${ }^{7}$ Entende-se por sistema de uma edificação a maior parte funcional dela, representada por um conjunto de elementos e componentes destinados a cumprir com uma macrofunção que a define (por exemplo, fundação, estrutura, vedações verticais, instalações elétricas e cobertura) (ABNT, 2008).
} 


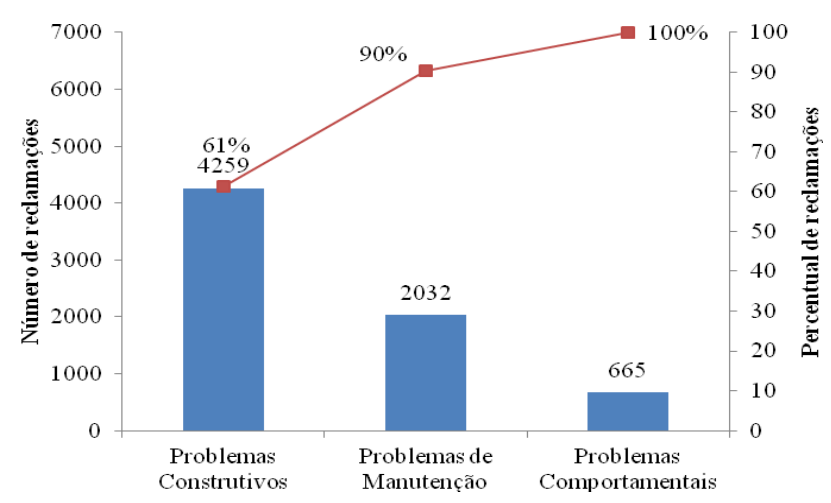

Figura 2 - Pareto das reclamações quanto à natureza

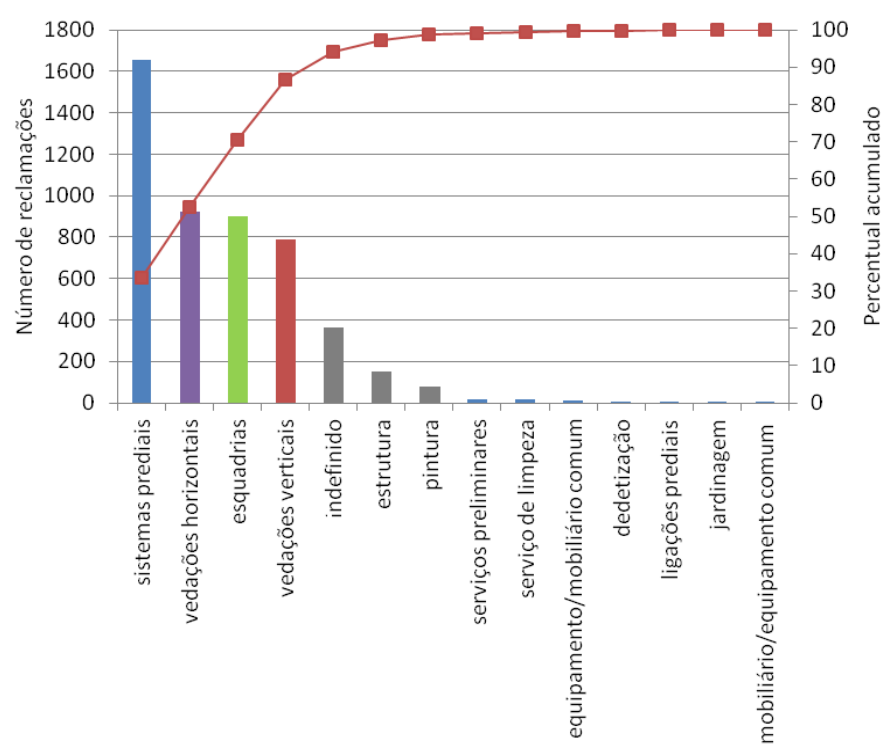

Figura 3 - Pareto das reclamações de problemas construtivos por sistema

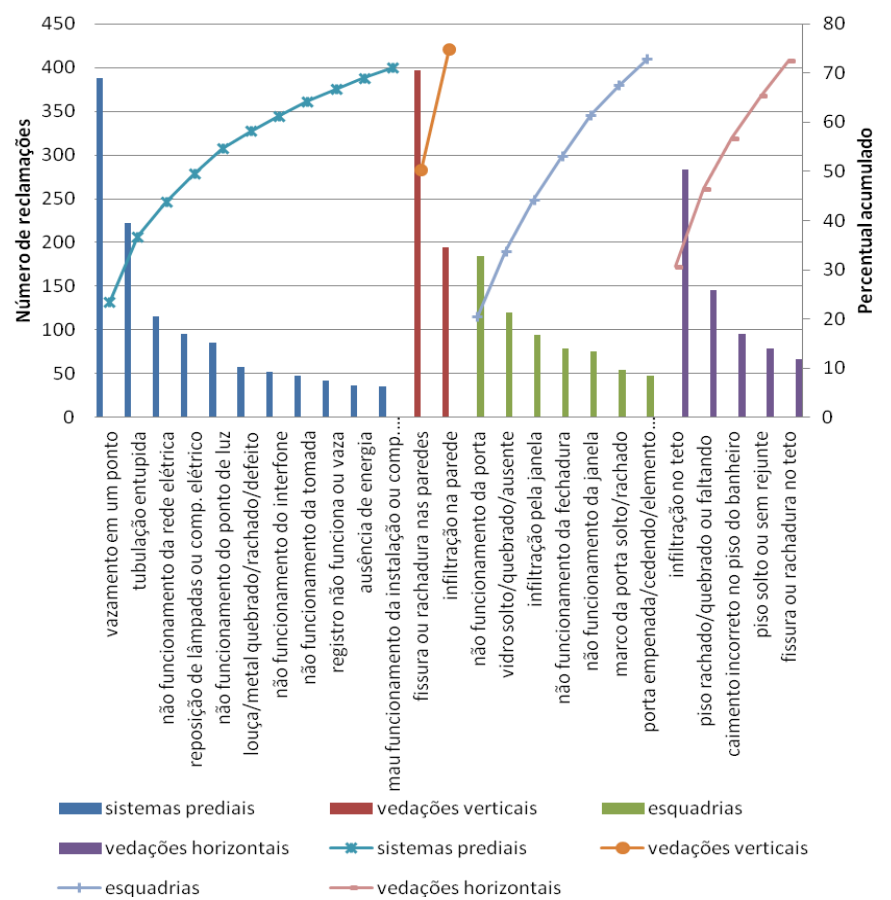

Figura 4 - Pareto das reclamações de problemas construtivos dos principais sistemas

158 Brito, J. N. de S.; Formoso, C. T.; Echeveste, M. E. S. 
A infiltração nos tetos, a presença de pisos rachados ou danificados e o caimento incorreto do piso do box dos banheiros são os problemas mais frequentes nas reclamações de vedações horizontais. Nota-se que as infiltrações correspondem a $30 \%$ das reclamações relacionadas aos tetos, podendo esse problema estar relacionado com a má execução da rede hidrossanitária ou com um projeto inadequado. A reclamação de piso rachado, quebrado ou ausente pode estar relacionada tanto com a qualidade do material, quanto com a falta de cuidado no assentamento. $\mathrm{O}$ caimento incorreto do piso do box possivelmente está relacionado à falha de execução e à ausência de detalhamento de projeto.

Considerando que a empresa construtora pode ser um fator determinante no número de reclamações de problemas construtivos, realizou-se uma análise do sistema mais crítico em cada empresa construtora (Figura 5).

Em $61 \%$ das empresas analisadas, os sistemas prediais apresentam-se como os mais críticos se comparados aos demais sistemas, corroborando com a análise de frequência geral apresentada anteriormente. No entanto, em 39\% das empresas, outros sistemas como, por exemplo, vedações verticais e horizontais, são apontados como os mais críticos na geração de reclamações. Com base nesse indicador é possível que determinada empresa construtora concentre seus esforços para a melhoria na execução do processo mais crítico.

De acordo com a análise apresentada na Figura 5, os dados de reclamações podem ser utilizados pelas próprias empresas na identificação de seu desempenho comparado às demais do mesmo setor. Além disso, as reclamações podem ser uma importante informação para auxiliar os tomadores de decisão no ato de escolha ou contratação dessas empresas. Nesse sentido, por meio de testes estatísticos, analisaram-se as reclamações de problemas construtivos com o objetivo de classificar as empresas construtoras em agrupamentos com médias de reclamações significativamente diferentes, além de identificar a média de reclamações para cada uma delas, a fím de possibilitar um benchmarking.

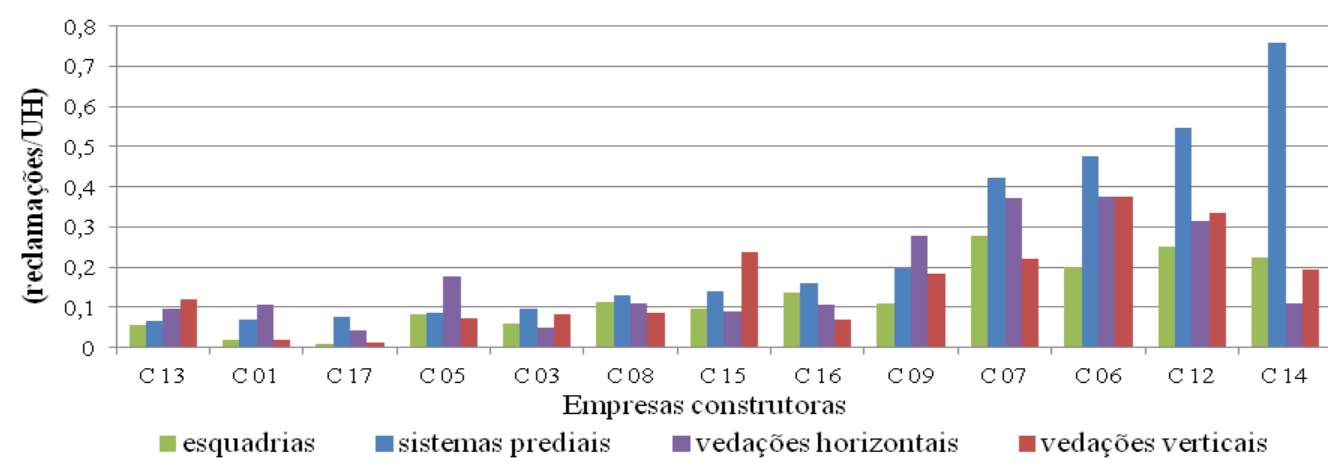

Figura 5 - Reclamações de problemas construtivos

Tabela 1 - Agrupamento das construtoras quanto ao índice de reclamações/unidade habitacional (problemas construtivos)

\begin{tabular}{|c|c|c|c|c|c|c|c|c|}
\hline \multirow[t]{2}{*}{ Construtora } & \multirow[t]{2}{*}{$\mathrm{N}^{\mathbf{0}} \mathrm{UH}$} & \multicolumn{2}{|c|}{ Alpha $=.05$} & \multirow[b]{2}{*}{3} & \multirow[b]{2}{*}{4} & \multirow[b]{2}{*}{5} & \multirow[b]{2}{*}{6} & \multirow[b]{2}{*}{7} \\
\hline & & 1 & 2 & & & & & \\
\hline Construtora 17 & 360 & 0,00 & & & & & & \\
\hline Construtora 01 & 200 & 0,03 & 0,03 & & & & & \\
\hline Construtora 05 & 97 & & 0,18 & 0,18 & & & & \\
\hline Construtora 08 & 200 & & 0,19 & 0,19 & & & & \\
\hline Construtora 13 & 92 & & & 0,20 & & & & \\
\hline Construtora 03 & 200 & & & 0,29 & & & & \\
\hline Construtora 16 & 468 & & & & 0,49 & & & \\
\hline Construtora 15 & 330 & & & & 0,57 & 0,57 & & \\
\hline Construtora 09 & 172 & & & & 0,65 & 0,65 & & \\
\hline Construtora 07 & 822 & & & & & 0,69 & & \\
\hline Construtora 06 & 80 & & & & & & 1,21 & \\
\hline Construtora 12 & 410 & & & & & & 1,32 & 1,32 \\
\hline Construtora 14 & 108 & & & & & & & 1,41 \\
\hline Sig. & 3.539 & 1 & 0,0575 & 0,4843 & 0,0513 & 0,4412 & 0,6377 & 0,8263 \\
\hline
\end{tabular}


As empresas foram comparadas utilizando-se o número de reclamações efetuadas no primeiro ano de ocupação dos empreendimentos. Para isso, efetuou-se uma análise de variância (One Way ANOVA) ${ }^{8}$ que, quando apresenta diferença significativa, é complementada pelo procedimento de Tukey, cujo objetivo é a comparação múltipla de médias. No teste consideraram-se 21 empreendimentos da base de dados que possuíam registros de reclamação em seu primeiro ano de ocupação, representando o total de 3.539 unidades habitacionais, nas quais foram registradas 2.581 reclamações.

Após a realização da ANOVA ( $p$ value $<0,001$ ), procedeu-se ao teste de Tukey, o qual apontou uma diferença significativa entre três agrupamentos de empresas construtoras, conforme indicado na Tabela 1:

(a) construtoras com menor incidência de reclamações $(0,00$ a 0,29 reclamação por unidade habitacional);

(b) construtoras com uma incidência intermediária de reclamações $(0,49$ a 0,69 reclamação por unidade habitacional); $\mathrm{e}$

(c) construtoras com incidências mais elevadas de reclamações $(1,21$ a 1,41 reclamação por unidade habitacional).

Na Tabela 1 é apresentado o valor médio de reclamações por unidade habitacional. As linhas tracejadas indicam os grupos entre os quais há diferenças significativas.

Observa-se que o grupo das empresas representado na parte inferior da tabela possui médias muito superiores em relação às demais. No caso dos empreendimentos estudados, os quais são promovidos pelo Governo Federal, a escolha das empresas é responsabilidade do Estado. Dessa forma, a identificação das médias de reclamações por unidade habitacional das empresas atuantes no mercado, bem como o agrupamento delas, poderia ser uma informação útil ao poder público, o qual pode atuar de forma intensa na fiscalização da execução das empresas mais problemáticas, bem como determinar níveis de exigências a essas empresas na busca de reduzir as altas médias de reclamações.

\section{Problemas de manutenção}

Foi realizada uma análise descritiva de frequência de 645 reclamações relacionadas aos problemas de manutenção. Os sistemas prediais e as esquadrias foram os que mais apresentaram reclamações, conforme indica a Figura 6.

A Figura 7 apresenta detalhadamente as reclamações dos sistemas prediais e esquadrias. Nos sistemas prediais, verificou-se que as reclamações com maior percentual são os vazamentos e entupimentos de tubulações e a necessidade de reposição de lâmpadas ou componentes elétricos. O problema de tubulação entupida pode estar relacionado ao mau uso dos equipamentos hidrossanitários. A partir das discussões com profissionais do agente financiador dos empreendimentos, foi possível identificar que várias reclamações sobre entupimento estavam relacionadas a objetos sólidos jogados no vaso sanitário e à gordura e resíduos sólidos despejados em ralos de pias e lavatórios. As ações dos usuários para a boa manutenção dos imóveis é incentivada por um trabalho social realizado previamente à ocupação dos empreendimentos. Com isso, cabe questionar se os agentes sociais, na representação do órgão financiador, estão cumprindo com seus objetivos ou se tais reclamações estão realmente associadas ao comportamento indevido dos usuários.

Em relação às esquadrias, o não funcionamento das portas e a falha nos vidros são as reclamações mais incidentes. Em discussões com os síndicos dos empreendimentos, realizadas junto à empresa administradora, eles ressaltaram que a inadequada utilização dos espaços comuns e a má qualidade das esquadrias de alumínio fazem com que os vidros se quebrem facilmente. Um problema apontado por eles foi a fragilidade das esquadrias, que, em sua maior parte, não preveem bandeiras fixas de alumínio na parte inferior das portas, propiciando a quebra ou a danificação dos vidros. A colocação de bandeiras fixas na parte inferior das portas, o reforço dos perfis de alumínio ou a substituição do material das esquadrias das áreas comuns podem contribuir para a diminuição dessas reclamações.

No caso das reclamações de entupimento e de quebra de vidros, verificou-se que os problemas apontados podem não estar relacionados diretamente com o desempenho da gestão condominial, mas sim representar falhas ocorridas pela má qualidade dos materiais, pelo mau uso do empreendimento e suas instalações, além de danos causados por atos de vandalismo. Dessa forma, se a causa do problema não estiver relacionada à gestão do uso, é preciso concentrar esforços em outras etapas do processo de desenvolvimento de empreendimentos habitacionais.

\footnotetext{
${ }^{8} \mathrm{~A}$ análise One Way ANOVA utilizada é disponibilizada no software SPSS versão 13.0 para Windows.
} 


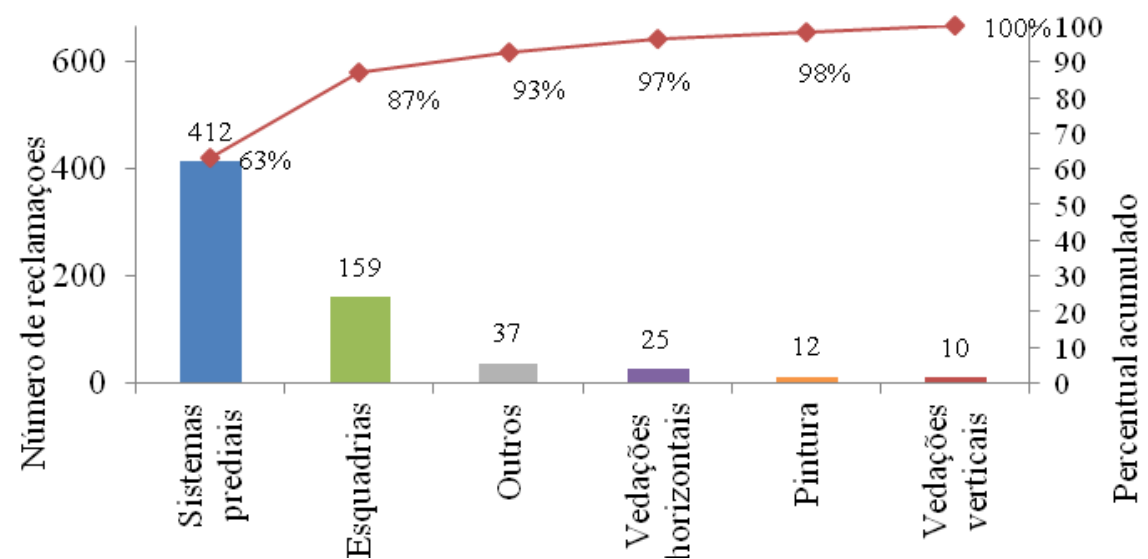

Figura 6 - Reclamações de problemas de manutenção por sistema

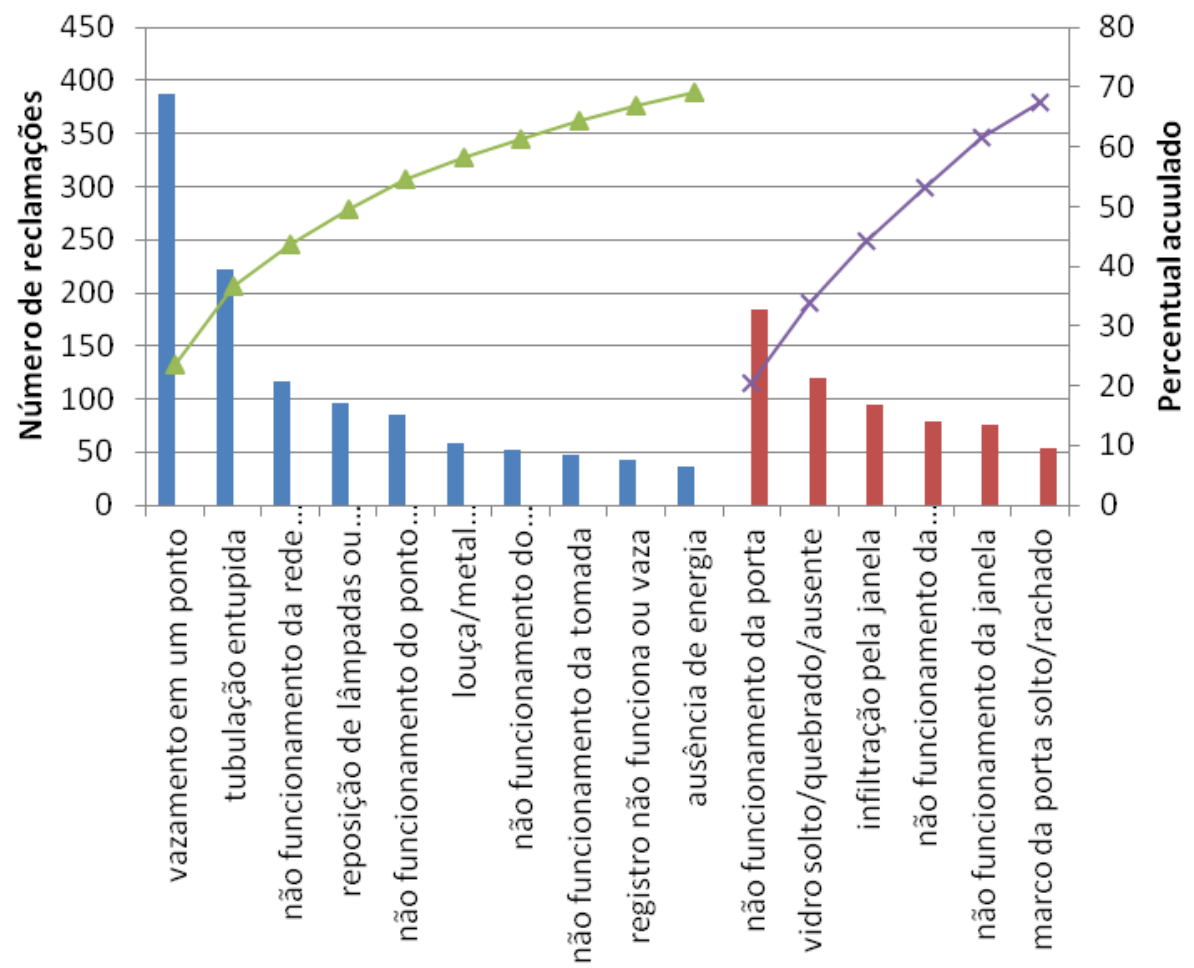

sistemas prediais

esquadrias

$\longrightarrow$ sistemas prediais

esquadrias

Figura 7 - Reclamações de problemas de manutenção dos sistemas prediais e esquadrias

No caso do PAR, os usuários recebem um trabalho técnico social (TTS) antes ou durante o primeiro ano de ocupação dos empreendimentos. Nessa fase, os usuários recebem instruções para a boa manutenção da propriedade, o que pode influenciar as reclamações de problemas de manutenção. Para entender essa relação realizou-se um teste-t de amostras independentes com base nas principais reclamações de problemas construtivos para os empreendimentos com no mínimo três anos de ocupação, comparando empreendimentos que receberam TTS e empreendimentos que não o receberam. O objetivo foi identificar se o TTS influencia a ocorrência de reclamações dos principais problemas de manutenção.

Primeiramente, consideraram-se para esta análise os problemas de manutenção que possam ter ocorrido em função da falta de manutenção pelo usuário ou por ações comportamentais deles, as quais podem ter danificado componentes e equipamentos dos empreendimentos habitacionais. Posteriormente, calculou-se a média de todos os problemas em função da realização do trabalho técnico social. A Tabela 2 representa a amostra referente aos três primeiros anos de ocupação, o 
número de reclamações e as médias. A Tabela 3 representa os resultados do teste-t para os três anos de ocupação dos empreendimentos.

O teste confirmou a hipótese de que a realização do trabalho social influencia a incidência de reclamações sobre problemas de manutenção (p value $<0,01)$, sendo que os empreendimentos que receberam esse trabalho possuem médias menores de reclamações por unidade habitacional. Embora o teste tenha revelado uma relação significativa entre a não realização do trabalho técnico social e a incidência de problemas de manutenção, julga-se possível que tais problemas podem estar relacionados também com outros problemas, tal como a deficiência na gestão da operação e manutenção. No entanto, os dados analisados são referentes a uma administradora e por essa razão não é possível comparar processos de gestão diferentes.

\section{Problemas comportamentais}

Foi realizada uma análise descritiva de frequência das reclamações de problemas comportamentais, conforme a Figura 8. Observa-se que a presença de barulho, brigas, animais no condomínio e a utilização dos espaços comuns indevidamente são as reclamações mais frequentes.

Tabela 2 - Amostra utilizada no teste-t de amostras independentes dos problemas de manutenção x TTS

\begin{tabular}{ccccc}
\hline Reclamações & $\mathbf{N}^{\circ} \mathbf{U H}$ & TTS & $\mathbf{N}^{\circ}$ reclamações & Reclamações/UH \\
\hline \multirow{2}{*}{ Problemas de manutenção } & 742 & sim & 53 & 0,0714 \\
\cline { 2 - 5 } & 96 & não & 16 & 0,1667 \\
\hline
\end{tabular}

Tabela 3 - Teste-t de amostras independentes dos problemas de manutenção x TTS

\begin{tabular}{|c|c|c|c|c|c|c|}
\hline \multirow{2}{*}{$\begin{array}{l}\text { Reclamações dos problemas de } \\
\text { manutenção }\left(1^{\circ}, 2^{\circ} \text { e } 3^{\circ} \text { anos }\right)\end{array}$} & \multirow{2}{*}{ Hipóteses } & \multicolumn{2}{|c|}{ Teste de Levene } & \multirow{2}{*}{ Hipóteses } & \multicolumn{2}{|c|}{ Teste-t } \\
\hline & & $\mathbf{F}$ & Sig & & $t$ & Sig \\
\hline \multirow{2}{*}{$\begin{array}{l}\text { Tubulação entupida, porta ou batente com } \\
\text { cupim, não funcionamento do motor do } \\
\text { portão/porteiro eletrônico/cerca elétrica, } \\
\text { componente da instalação hidráulica } \\
\text { danificado, vazamento em um ponto }\end{array}$} & $\sigma^{2} 1=\sigma^{2} 2$ & \multirow[b]{2}{*}{30,62} & \multirow[b]{2}{*}{$\mathbf{0 , 0 0}$} & $\mu 1=\mu 1$ & $-2,97$ & 0,00 \\
\hline & $\sigma^{2} 1 \neq \sigma^{2} 2$ & & & $\mu 1 \neq \mu 1$ & $-2,28$ & 0,02 \\
\hline
\end{tabular}

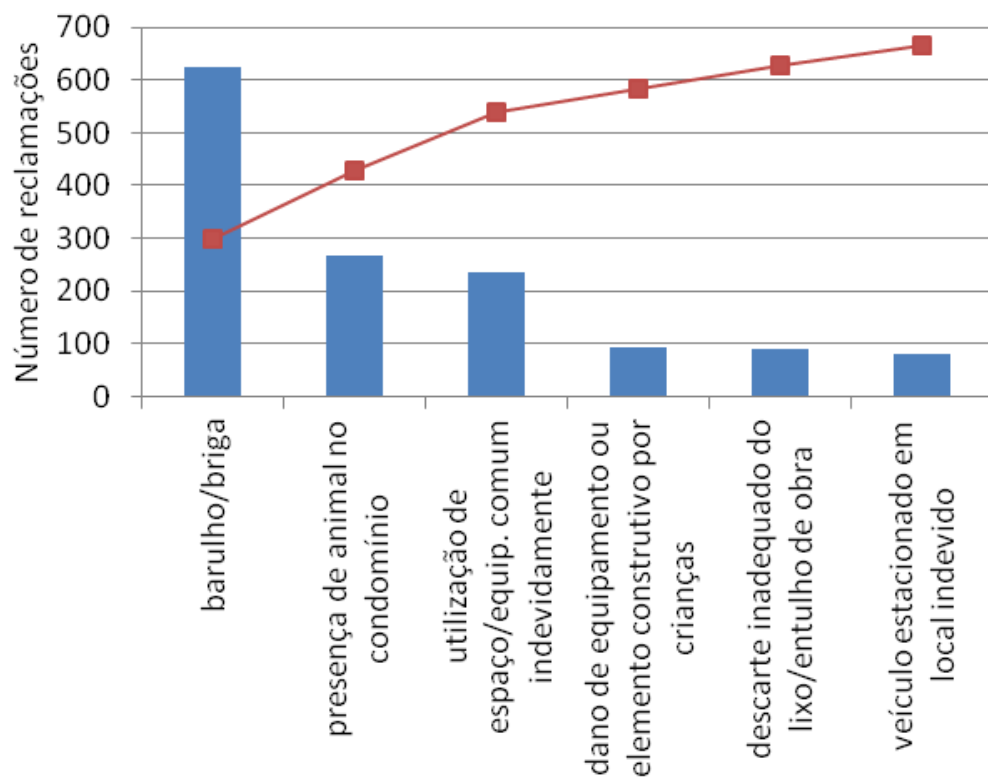

Figura 8 - Reclamações de problemas comportamentais 
Tabela 4 - Amostra utilizada no teste-t para comparação de tipologias e dos problemas comportamentais

\begin{tabular}{l|l|l|l}
\hline Reclamações dos problemas comportamentais & Tipologia & $\mathrm{N}(\mathrm{UH})$ & Média \\
\hline \multirow{2}{*}{ Barulho/Briga } & apartamento & 742 & $\mathbf{0 , 0 3 6}$ \\
& casa & 97 & 0,030 \\
\hline \multirow{2}{*}{ Presença de animal no condomínio } & apartamento & 742 & $\mathbf{0 , 0 1 4}$ \\
& casa & 97 & 0,006 \\
\hline Utilização de espaço/equipamento comum & apartamento & 742 & $\mathbf{0 , 0 1 2}$ \\
indevidamente & casa & 97 & 0,003 \\
\hline
\end{tabular}

Tabela 5 - Teste-t de amostras independentes dos problemas comportamentais $\mathrm{x}$ tipologia

\begin{tabular}{|c|c|c|c|c|c|c|}
\hline \multirow{2}{*}{$\begin{array}{l}\text { Reclamações dos } \\
\text { problemas } \\
\text { comportamentais }\left(1^{\circ}, 2^{\circ}\right. \\
\left.\text { e } 3^{\circ} \text { anos }\right)\end{array}$} & \multirow{2}{*}{$\begin{array}{l}\text { Hipóteses de } \\
\text { diferença de } \\
\text { variabilidade }\end{array}$} & \multicolumn{2}{|c|}{ Teste de Levene } & \multirow{2}{*}{$\begin{array}{l}\text { Hipóteses } \\
\text { de teste de } \\
\text { médias }\end{array}$} & \multicolumn{2}{|c|}{ Teste-t } \\
\hline & & $\mathrm{F}$ & Sig. & & $\mathrm{T}$ & $\mathrm{p}$ value \\
\hline \multirow{2}{*}{ Barulho/Briga } & $\sigma_{1}^{2}=\sigma_{2}^{2}$ & \multirow{2}{*}{11,52} & \multirow{2}{*}{$\mathbf{0 , 0 0}$} & \multirow{2}{*}{$\begin{array}{l}\mu_{1}=\mu_{2} \\
\mu_{1} \neq \mu_{2}\end{array}$} & 1,86 & 0,06 \\
\hline & $\sigma_{1}^{2} \neq \sigma_{2}^{2}$ & & & & 2,00 & 0,05 \\
\hline \multirow{2}{*}{$\begin{array}{l}\text { Presença de animal no } \\
\text { condomínio }\end{array}$} & $\sigma_{1}^{2}=\sigma_{2}^{2}$ & \multirow{2}{*}{2,52} & \multirow{2}{*}{0,11} & \multirow{2}{*}{$\begin{array}{l}\mu_{1}=\mu_{2} \\
\mu_{1} \neq \mu_{2}\end{array}$} & $-1,08$ & 0,28 \\
\hline & $\sigma^{2}{ }_{1} \neq \sigma_{2}^{2}$ & & & & $-1,06$ & 0,29 \\
\hline \multirow{2}{*}{$\begin{array}{l}\text { Utilização de } \\
\text { espaço/equipamento } \\
\text { comum indevidamente }\end{array}$} & $\sigma_{1}^{2}=\sigma_{2}^{2}$ & \multirow[b]{2}{*}{26,12} & \multirow[b]{2}{*}{$\mathbf{0 , 0 0}$} & \multirow{2}{*}{$\begin{array}{l}\mu_{1}=\mu_{2} \\
\mu_{1} \neq \mu_{2}\end{array}$} & $-3,30$ & 0,00 \\
\hline & $\sigma^{2}{ }_{1} \neq \sigma_{2}^{2}$ & & & & $-3,01$ & 0,00 \\
\hline
\end{tabular}

As características espaciais do ambiente construído são apontadas por alguns autores como fatores determinantes do comportamento das pessoas que frequentam esses espaços (LYNCH, 1960; LAY, 2005a; LAY; REYS, 2005b). Com base nisso, buscou-se testar se a tipologia arquitetônica influencia as reclamações de problemas comportamentais realizadas pelos usuários de sete empreendimentos habitacionais com três anos de ocupação, totalizando 839 unidades habitacionais. Os empreendimentos avaliados foram classificados em duas diferentes tipologias arquitetônicas: apartamentos e casas (casas térreas ou sobrados).

Para testar essa hipótese realizou-se o teste de Levene, seguido de um teste- $t$ para amostras independentes. A Tabela 4 representa a amostra válida para os três primeiros anos de ocupação, o número de reclamações e as médias da amostra analisada. A Tabela 4 representa os resultados do teste- $t$ para os sete empreendimentos avaliados.

O teste de Levene atesta a suposição de igualdade de variâncias para a realização do teste de médias. Nos resultados apresentados na Tabela 5, observase a não equivalência de variâncias para as variáveis que representam as reclamações referentes a barulho e briga, e utilização de espaços ou equipamentos incomuns indevidamente ( $p$ value $<0,001$ para ambas). Para essas variáveis utilizou-se o teste de médias com variâncias não equivalentes $\left(\sigma^{2}{ }_{1} \neq \sigma_{2}^{2}\right)$.
O teste de médias apontou que a tipologia interfere na ocorrência de reclamações referentes a barulho e briga ( $p$ value $=0,05$ ), ou seja, há evidências de que o valor médio das reclamações de barulho e briga diferencia-se de acordo com a tipologia arquitetônica, sendo maior para apartamentos $\left(\mu_{1}\right)$ e menor para casas ou sobrados $\left(\mu_{2}\right)$. A tipologia também interfere na ocorrência de reclamações referentes à utilização de espaço/equipamento comum indevidamente ( $p$ value $<0,001$ ), sendo maior para apartamentos $\left(\mu_{1}\right)$ e menor em casas ou sobrados $\left(\mu_{2}\right)$, o que pode estar relacionado com soluções de projeto que negligenciam espaços para atividades de lazer, influenciando o comportamento dos usuários. Esse fato faz com que os moradores utilizem os espaços coletivos de circulação ou outras funcionalidades para exercer atividades de lazer, sustentando a opinião de alguns autores que afirmam que características físicas e espaciais de um projeto habitacional podem influenciar o comportamento das pessoas (BLANCO et al., 2003; LAY, REIS, 2005a; LAY; REIS, 2005b).

A tipologia arquitetônica, entretanto, não interfere em reclamações oriundas da presença de animal no condomínio ( $p$ value $=0,28$ ). Nota-se que, embora as médias de reclamação pareçam distantes, 0,014 para apartamentos e 0,06 para casas, não foi identificada diferença estatisticamente significativa entre elas. Com isso, não há evidências de que os conflitos gerados pela presença dos animais estão 
relacionados à tipologia arquitetônica do empreendimento.

\section{Conclusões}

O registro de reclamações de usuários de empreendimentos habitacionais possui um grande potencial na geração de informações que podem auxiliar os tomadores de decisão na provisão habitacional. Diversas etapas do processo de desenvolvimento de empreendimentos habitacionais de interesse social podem ser retroalimentadas com indicadores gerados a partir do processamento e análises dessas informações, auxiliando a tomada de decisão dos agentes envolvidos.

Embora os indicadores gerados nesta pesquisa possam ter limitações em função do grau de precisão das informações, eles indicam a existência de problemas e podem ser considerados como indicadores de visibilidade. Ou seja, podem ser utilizados para identificar pontos fortes e fracos, a fim de indicar áreas que necessitam mais atenção, normalmente mediante uma investigação mais aprofundada (SINK; TUTTLE, 1993). No entanto, devido à natureza dos dados, recomendase que esses indicadores sejam utilizados em conjunto com outras evidências. Entre as principais decisões que podem ser tomadas a partir desses indicadores destacam-se a definição da tipologia arquitetônica em função dos problemas comportamentais, a contratação de empresas construtoras em relação à média de reclamações por sistemas e o planejamento de um acompanhamento técnico social aos moradores em função dos problemas de manutenção identificados.

O estudo destacou como algumas informações podem ser úteis às etapas de projeto, execução e gestão da operação e manutenção, como se segue:

(a) projeto: identificação de problemas comportamentais que estão relacionados com soluções de projeto; identificação das falhas construtivas mais frequentes, as quais podem ter origem no projeto; identificação dos principais problemas de manutenção, a fim de contribuir com a especificação de materiais mais duráveis ou com o desenvolvimento de soluções de projeto que minimizem tais problemas;

(b) execução: identificação das empresas construtoras contratadas que mais apresentam reclamações; identificação das falhas construtivas mais frequentes, as quais podem ter origem na execução; e

(c) gestão da operação e manutenção:

identificação das principais falhas de manutenção, identificação dos problemas comportamentais, a fim de alinhar as ações de gestão dos espaços pela administradora.

O entendimento da utilidade das reclamações na construção civil é importante para o segmento de habitação de interesse social, uma vez que a obtenção desses dados pode ser realizada facilmente e sem custos elevados, se comparada a outras formas de retroalimentação do processo de desenvolvimento do produto. Com isso, destaca-se a importância da continuidade dos estudos sobre reclamações de usuários de empreendimentos habitacionais de interesse social, nos quais os problemas de qualidade têm tido grande incidência. Como sugestão de futuros trabalhos aponta-se a necessidade de melhoria das bases de dados de reclamações no setor habitacional, através da gestão das reclamações.

\section{Referências}

ANG, L.; BUTTLE, F. CustomerRretention Management Process: a quantitative study. European Journal of Marketing, v. 40, n. 1/2, p. 83-99, 2006.

\section{ASSOCIAÇÃO BRASILEIRA DE NORMAS \\ TÉCNICAS. NBR 15575-1: edifícios \\ habitacionais de até cinco pavimentos: desempenho. Rio de Janeiro: ABNT, 2008.}

BARLOW, J.; MOLLER, C. Reclamação de Cliente? Não tem melhor presente: usando o feedback do cliente como uma ferramenta estratégica. São Paulo: Futura, 1996.

BLANCO, A. T.; MARTÍNEZ, P. J.; JARPA, L. G. Análisis e Incorporación de Factores de Calidad Habitacional em el Ddiseño de lãs Vivendas Sociales em Chile: propuesta metodológica para um enfoque integral de la calidad residencial. Boletín INVI, v. 18, n. 46, p. 9-21, jan. 2003.

CHURCHILL, G. A., PETER JUNIOR., J. P. Marketing: criando valor para os clientes. São Paulo: Saraiva, 2000. 626 p.

DUNOWICZ, R.; HASSE, R. Diseño y Gestión de la Vivienda. Revista INVI, v. 20, n. 54, p. 85-103, ago. 2005.

ESTELAMI, H. Competitive and Procedural Determinants of Delight and Disappointment in Consumer Complaint Outcomes. Journal of Service Research, v. 2, n. 3, p. 285-300, 2000.

FELD, J. Construction Failure. New York: John Wiley \& Sons, 1968. 
FERNANDES, D. H. O Comportamento de Retaliação do Consumidor e Seus Antecedentes. 130 f. Porto Alegre, 2008. Dissertação (Mestrado em Administração) - Escola de Administração, Universidade Federal do Rio Grande do Sul, Porto Alegre, 2008.

FISHER, J. E. et al. Dissatisfied Consumers Who Complain to the Better Bussiness Bureau. Journal of Consumer Marketing, v. 16, n. 6, p. 576-589, 1999.

FUNDIN, A. P.; BERGMAN, B. L. S. Exploring the Customer Feedback Process. Measuring Business Excellence, v. 7, n. 2, p. 55-65, 2003.

HUPPERTZ, J. W. Firms' Complaint Handling Policies and Consumer Complaint Voicing. Journal of Consumer Marketing, v. 27, n. 7, p. 428-437, 2007.

JAMBEKAR, A. B.; PELC, K. I. A Model of Knowledge Processes in a Manufacturing Company. Journal of Manufacturing

Technology Management, v. 17, n. 3, p. 315-331, 2005.

KIM, C. The Effect of Attitude and Perceptions on Consumer Complaint Intentions. Journal of Consumer Marketing, v. 20, n. 4, p. 352-372, 2003.

LAY, M. C. D.; REIS, A. T. L. Habitação Social: diferenças no papel de espaços abertos segundo tipos habitacionais. In: ENCONTRO NACIONAL DA ASSOCIAÇÃO NACIONAL DE PÓSGRADUAÇÃO E PESQUISA EM PLANEJAMENTO URBANO E REGIONAL, 14., Salvador, 2005. Salvador, BA. Anais... ANPUR, 2005a.

LAY, M. C. D.; REIS, A. T. L. Análise Quantitativa na Área de Estudos AmbienteComportamento. Revista Ambiente Construído, Porto Alegre, v. 5, n. 2, p. 21-36, abr./jun. 2005 b.

LYNCH, K. The image of the city. Cambridge: MIT Press, 1960.

RAVALD, A.; GRÖNROOS, C. The Value Concept and Relationship Marketing. European Journal of Marketing, v. 30, n. 2, p. 19-30, 1996.

REIS, A. Relação Entre Níveis de Manutenção, Limpeza, Personalização, Aparência, Satisfação e Principais Alterações Realizadas nas Habitações. In: ENCONTRO NACIONAL DE TECNOLOGIA DO AMBIENTE CONSTRUÍDO, 7., Florianópolis, 1998. Anais... Florianópolis: UFSC, 1998. p. 597-604.
RICHTER, C. Qualidade da Alvenaria Estrutural em Habitações de Baixa Renda: uma análise da confiabilidade e da conformidade. $175 \mathrm{f}$. Porto Alegre, 2007. Dissertação (Mestrado em Engenharia) - Programa de Pós-graduação em Engenharia Civil, Universidade Federal do Rio Grande do Sul, Porto Alegre, 2007.

ROZENFELD, H. et al. Gestão de Desenvolvimento de Produto: uma referência para a melhoria do processo. São Paulo: Saraiva, 2006.

RUST, R. T.; STEWART, G. L. The Satisfaction and Retention of Frontline Employees. International Journal of Service Industry Management, v. 7, n. 5, p. 62-80, 1996.

SALIBA, M.; FISHER, C. Managing Customer Value: a framework allows organizations to achieve and sustain competitive advantage. Quality Progress, Milwaukee, v. 33, n. 6, p. 6369, jun. 2000.

SAMPSON, S. E. An Empirically Defined Framework for Designing Customer Feedback Systems. Quality Management Journal, v. 6, n. 3, p. 64-80, 1999.

SEELEY, I. H. Building Maintenance. London: Macmillan, 1976.

SINGH, J. Consumer Complaint Intentions and Behavior: definitional and taxonomical issues. Journal of Marketing, v. 52, n. 1, p. 93-108, 1988.

SINK, D. S.; TUTTLE, T. C. Planejamento e Medição Para a Performance. Rio de Janeiro: Qualitymark, 1993.

SOUZA, R. Normalização, Controle da Qualidade e Manutenção de Edifícios. In: SEMINÁRIO SOBRE MANUTENÇÃO DE EDIFÍCIOS: escolas, postos de saúde, prefeitura e prédios públicos em geral, Porto Alegre, 1988. Anais... Porto Alegre, 1988. v. 2, p. 1-15.

VOS, J. F. J.; HUITEMA, G. B. How Organisations Can Learn from Complaints. The TQM Journal, v. 20, n. 1, p. 8-17, 2008.

YU, S. M.; HAN, S. S. Information Systems in Public Housing Management: case study of a town council in Singapore. Facilities, v. 19, n. 5/6, p. 233-239, 2001. 


\section{Revista Ambiente Construído}

Associação Nacional de Tecnologia do Ambiente Construído Av. Osvaldo Aranha, $99-3^{\circ}$ andar, Centro

Porto Alegre - RS - Brasil

CEP $90035-190$

Telefone: +55 (51) 3308-4084

Fax: +55 (51) 3308-4054

www.seer.ufrgs.br/ambienteconstruido

E-mail: ambienteconstruido@ufrgs.br

166 Brito, J. N. de S.; Formoso, C. T.; Echeveste, M. E. S. 